\title{
El erotismo en Xesús Rábade Paredes
}

\author{
Consuelo Brito de Freitas
}

Etimológicamente, erótico se origina de erotikós (relativo al amor) y deriva de Eros, el dios del amor de los griegos, Cupido entre los romanos. Marcuse (1968:77).

El erotismo representa, así, el resultado de la conjunción entre erot(o) + ismo y significa, pasión amorosa, amor lúbrico. Es un asunto universal y recurrente en todos los lugares y momentos históricos.

Al leer estos poemarios y, también, comentarios sobre esta temática, consideramos que el texto erótico se presenta como una representación que depende de la época, de los valores, de los grupos sociales, de las particularidades del autor, de las características de la cultura en que fue elaborada.

Como afirma Octavio Paz (1996: 232) a propósito del erotismo, nada más natural que el deseo sexual, nada menos natural que las formas en que se manifiesta y se satisface. En el lenguaje, continúa Paz, y en la vida erótica de todos los días, los participantes imitan los rugidos, relinchos, arrullos y gemidos de toda especie de animales. La imitación no pretende simplificar, pero complicar el juego erótico y así acentuar su carácter de representación. (pág. 233).

El erotismo no imita la sexualidad, es su metáfora. El texto erótico es la representación textual de esta metáfora. Podría incluso contemplarse, desde el punto de vista del psicoanálisis freudiano, la analogía que existe entre erotismo como metáfora del sexo y, a su vez, el amor romántico como sublimación inconsciente de lo sexual entendido como erotismo. El amor en realidad es el sexo encubierto, de ahí que etimológicamente lo erótico sea lo sexual. Y el amor romántico la expresión de esa sexualidad oculta.

Los poemas que analizaremos pertenecen a la obra Poldros de Música (1994). Los componentes que están presentes en la expresión erótica son $t i, e u$ y natureza. 
La nueva estética que utiliza el autor rompe con el arte métrico tradicional. No sigue estrictamente el cómputo silábico y desprecia particularmente la rima, la métrica en general. Para algunos poetas nuevos la meta no es ya la musicalidad del verso, tal y como afirma Navarro Durán (1998: 38) sin rima, sin medida, sin estrofas, los versos -libres-siguen hoy con su melodía, con su música. El verso es la unidad musical de la expresión literaria; y el ritmo lo que determina esa musicalidad.

Almeida Cara (1998: 40) afirma que el poeta moderno sabe perfectamente que cualquier recorte del mundo será apenas lenguaje y no es posible más que eso: el poeta moderno se ve proyectado en el mundo exterior, sabiendo que de éste podrá hacer apenas una traducción parcial.

La escritura lírica del autor, Xesús Rábade Paredes ${ }^{l}$, se caracteriza por su gran coherencia y por sus constantes temáticas y vivencias, que justifican la alusión musical que aparece en el título del libro Poldros de Música. Los dos sustantivos que lo componen tienen claras connotaciones. Poldros significa cabalo de pouca idade. Entonces, Poldros de Música sería una nueva melodía, una nueva canción de amor. Sus tres partes componen el todo de la canción, es decir, el himno al objeto del deseo, la mujer, presente en todo este poemario.

En el prologo de la referida obra hecho por el crítico literario Anxo Tarrío Varela (1994: 9), Rábade Paredes es considerado el poeta del Realismo Social, aunque en sus últimas publicaciones poéticas, y en particular en ésta, la temática dominante es el Amor y el Erotismo, a través de una visión retrospectiva de la trayectoria del autor, y nos presenta la obra de la que hemos seleccionado nueve poemas que comentaremos a continuación.

El libro está dedicado a su compañera Helena y está dividido en tres partes. La primera parte se llama - PRELUDIO — (pág. 15) la abre con dos citas, seguidas de ocho poemas; la segunda parte -PRESENCIA- (pág. 35) la inicia con dos citas, seguidas de trece poemas, y la tercera - PARA DESPOIS(pág. 65) también comienza con dos citas a la que le siguen trece poemas.

El canto al amor está en todos los poemas. El deseo por la amada está siempre presente. La aproximación silenciosa del amado es paulatina como se puede confirmar en estos versos / Veño de parte incógnita, / desde o descoñecido,/sombra nada na sombra./Chego cabo de ti no ser da anoitecida/(pág. 19).

En la segunda estrofa la lluvia está presente. La lluvia es muy excitante, sensual y el sonido de ella es como una canción de amor. En el Diccionario de Símbolos (1986: 650) la lluvia es universalmente considerada como el símbolo de las influencias celestes recibidas por la tierra. Es un hecho evidente que constituye el agente fecundador del suelo, de él se obtiene la fertilidad. (...) El

' Es catedrático de Lengua y Literatura en el Instituto Rosalía de Castro. Como poeta, narrador y ensayista desde los años 80 , recibió algunos de los premios literarios más importantes del país, entre ellos, Manuel Antonio, Galicia y Lorenzo Varela, de poesía el Galicia, Alvaro Cunqueiro de narrativa, y el XIII Premio de Esquio, por su obra Poldros de Música, que analizamos. 
simbolismo sexual de la lluvia considerada como esperma y el simbolismo agrario de la vegetación que necesita la lluvia para florecer, se une aquí estrechamente. Los pájaros, las flores y el cielo con el arco de colores decoran esta melodía. Confirmamos esta afirmación en el Diccionario de los Símbolos (1986: 135) cuando Chevalier afirma que el arco iris es a menudo el símbolo del puente entre el cielo y la tierra. Expresa siempre y en todo lugar unión, relación e intercambio entre ambos.

El deseo es tan intenso, que con la metáfora / Veño a ti feito río moi anchuroso e escuro / (pág. 19) penetra con una profundidad, hecho una tempestad, una lluvia muy fuerte. El poeta evoca el amor de una forma muy sensual, el placer corporal está latente. La sensación que produce es que la palabra está tocando el cuerpo. Consideramos que en este poema hay una analogía con la lluvia, el agua y el placer de la mujer.

Este poema, quinto de la primera parte del libro, manifiesta el deseo por la amada ya en el primer verso / Porque así te aprendín e así te quero,/(pág. 27).

El sueño del autor, su imaginario es tener una mujer pura, que expresa con impulsos incontenibles y apasionados. El sentimiento por la mujer tal cual es, es decir, el respeto por el ser con sus diferencias / lenta cerva sublime /(pág. 27)2.

El poeta describe en todo el poema cómo desea a su amada /eda e tamén de rostro melancólico,/fermosa en cabeleira boiante polos ombros /(pág. 27)

En la segunda parte, el poeta transmite el amor a la amada mezclado con la naturaleza, con las plantas aromáticas, cuya relación con el sexo es innegable como podemos confirmar en estos versos / Sobre cama de ourego, / deusa miña profunda feita de azul e escuma,/ (pág. 45).

Cuando se ama de verdad, una de las regiones del cuerpo mas dulces, más tiernas son las pálpebras, y el autor tiene esa sensibilidad al decir / chégasme de horizonte collido nas túas pálpebras / e un acoro de música abrollando na carne... (pág. 45).

El color azul de nuestro cielo, es decir, amando al aire libre y la música penetrando en la carne y también los pájaros cantando en bandadas y amando hasta la muerte. (...) Negar la muerte, porque el sexo, el amor, el erotismo, es lo contrario de Thánatos en Freud. Es la exaltación de la vida frente a la muerte Marcuse (1968: 45). Hay que vivir de amor y no morir de amor. Y la vida es para vivir el placer.

Podemos confirmar este sentimiento de vivir el amor en este poema, donde en el primer verso la presencia de la naturaleza es evidente / Ando nos teus canei$r o s, /($ pág. 55) caneiros, lugar donde hay canas, pequeño canal. Y también es el deseo de recorrer el cuerpo de la mujer, el placer carnal. Pero también caneiro es

2 La simbología fálica de este animal —cerv(a)— es antiquísima y común a culturas orientales y occidentales. Los poetas gallegos revitalizaron modernamente y rescataron su raigame amorosa. (X.L. AXEITOS, 1988: 148). 
una metáfora del sexo de la mujer. La presencia de las frutas con el sentido de saborearlas, es decir, el cuerpo de la amada son todas las frutas. El placer es tan grande que el sexo está ardiente. Y viven tan intensamente el momento amoroso que se olvidan de la realidad en estas estrofas / caendo corpo adentro, mundo adentro, / ata que as cousas todas esquezan os seus nomes/(pág. 55).

La forma de referirse el poeta a la geografía del cuerpo de la mujer es de una gran sensibilidad. Y también, la presencia de las plantas aromatizantes que son utilizadas como condimento afrodisíaco, por ejemplo: el loureiro muestra que está a la espera para la aproximación del cuerpo de la amada. Tentación miña, deusa, / que me chamas a berros coas formas do teu corpo/ que inmenso che devezo./ Agárdame na terra co arrecendo a loureiro/ (pág. 57).

En la segunda estrofa, el poeta va preparando la aproximación para vivir la plenitud del placer, rozando los cuerpos, pues el deseo es cada vez más intenso, acariciando un tipo de fruta muy característico como si fuese el cuerpo de la amada, es decir, el amante está saboreando el cuerpo de la amada. Nou gaveando ó cume./Subo estrullando nácares/ E descendo arelante polos teus vales múltiples/ (pág. 57).

El amor, el deseo del poeta por su amada, se percibe otra vez desde el primer verso en este poema /Heite levar comigo a onde o tempo nos ata./ E alí, no altar da Albela inzada de codesos, / brincarán de felices na tarde os nosos corpos ... (pág. 59).

El poeta envuelto con la naturaleza, describe los cuerpos que se ponen a brincar. La presencia de las plantas aromáticas estan también en este poema / Sobre as moutas de ourego, / deusa miña profunda feita de azul e escuma (pág. 59).

Las moutas son una mata espesa de plantas de poca altura. El ourego, son plantas aromatizantes, afrodisíacas. El poeta utiliza continuamente la metáfora relacionada con la vegetación, debido precisamente a la gran vegetación que existe en Galicia, que podría ser una analogía con toda la exuberancia de la mujer inspirada en el paisaje gallego.

El poeta con la repetición, confirma el sentimiento de deseo, de amor por la amada, fundiéndose dos en uno hasta la muerte.

El próximo poema que analizaremos es el primero de la última parte del libro que se titula Para despois. Asistimos a la exaltación del poeta, demostrando el sentimiento por la amada. Conoce de memoria su objeto del deseo, los lugares que siente el mayor placer. Pero el amor nace y renace con brillo en el día a día. La naturaleza, el lirismo siempre presente como si fuese el camino para el amor dando así una gran sensualidad a los versos / Somos reminiscencia, / muller, / de tantas cousas .../ Xa che sei de memoria/ cada volta, / cada sitio recóndito do corpo (pág. 69).

El poeta, muy apasionado por su amada, se refiere al cuerpo de la mujer de una forma bella y sublime. El sentimiento es tan ardiente, que el autor 
percibe a su amada como si se tratase de un estallido de la naturaleza. El amante se presenta como animal y niño al mismo tiempo ${ }^{3}$. Una infancia entendida como ese paraíso perdido de sexualidad polimórfica que se desea recobrar. El placer del niño no solamente es genital. El buen amante es como el niño. / Feito animal e neno,/ Abalareite en cimbros de abelaira vizosa/ E en cóxegas de vento (pág. 71).

El penúltimo poema del libro está dedicado a su mujer Helena, es una declaración de amor a su amada. El amor es como una explosión con versos melódicos, como se confirma en el primer verso /Maina mullher, Helena lenturenta/. (pág. 91) Maina, es decir tranquila, calma. (1995:944) Y lenturenta, "diz-se da terra que ten a suficiente lentura para haber vexetación" (1995: 910). Al mismo tiempo que la mujer es tan fuerte como la tierra, también es sensible y llora, aunque seduciéndole con su armonía y su hermosura el ser amado.

Una vez más el poeta describe el cuerpo de la amada de una forma muy erótica, utilizando la naturaleza para dar más intensidad al sentimiento. Se percibe la importancia de lo telúrico como algo que llega a ser panteísta, es decir, el sentimiento panteísta es la conjunción que el poeta hace de la tierra con el paisaje que es muy sensual / todo o lentor dos agros para nós,/ todo o rumor telúrico do cosmos/ para os nosos dous corpos tremecentes (pág. 91).

El sentimiento amoroso es tan fuerte que cuando llega a su plenitud, el poeta transmite la pérdida de toda consciencia, hasta de la identidad humana. /E perderan as chousas os seus nomes, / e os nomes dos seus donos/(pág. 91).

En la tercera estrofa el yo poético se entrega intensamente a la amada, se funden sus cuerpos para vivir la plenitud amorosa con un apasionamento instintivo e irracional. La descripción del cuerpo de la amada detenida, alentiza$\mathrm{da}$, intensifica el ardiente deseo del yo poético.

/ E arreguicei entón de darme enteirol Ás túas mans frementes e ós teus labio (pág. 92).

Y en la última estrofa se concretiza la relación de los amantes, su plenitud. / Un paxariño inquedo, insatisfeito,/ inzábache nas pernas entre as miña (pág. 92).

El poeta se refiere al pájaro. De acuerdo con CIRLOT (pág. 350), el pájaro es un símbolo de espiritualización. (...) Era en su origen un símbolo fálico, pero dotado de poder ascendente (sublimación y espiritualización). El colibrí inquedo ${ }^{4}$ (sen sosego, axitado, inquieto) al encuentro del cuerpo de su amada, I para ceibarse de ataduras vellas/ (pág. 92). Pero en este verso el poeta al decir ceibarse tiene deseos de soltar, desatar, dar libertad a su amada para vivir

\footnotetext{
Segun Marcuse (1968: 47) en la simbología freudiana, la parte instintiva del ser humano se corresponde con su animalidad, representada en la figura del niño.

+ Colibri, según el Diccionario da Língua Galega (1995) páxaro americano mui pequeño que pica o néctar das flores.
} 
un amor desinteresado, el amor ideal. Compartimos con Paz, cuando afirma que amor sin erotismo no es amor y erotismo sin sexo es impensable e imposible (pág. 97).

La relación existente entre poesía y lenguaje es una manifestación de la pasión por el lenguaje. La poesía es el amor entre los sonidos y los sentimientos. Es el acto de amor entre el cuerpo y la mente. Podemos decir que la poesía es la erotización del lenguaje, el principio del placer.

Para finalizar, Poldros de Musica es una obra que causa inquietud, pues se revela con esta temática, despojada de los tópicos anteriores, extremamente fascinante. Son textos repletos de vida y sensualidad, a través de los que el autor hace una introspección profunda de si mismo, explorando el cuerpo mientras busca, en la fluidez y sensualidad del lenguaje, la propia desnudez del alma.

\section{BIBLIOGRAFÍA}

Almeida Cara, Salete de (1998): A poesia lírica. 4. ${ }^{a}$ ed., Série Princípios. Ed. Ática, S. Paulo.

BELLI, Gioconda (1998): Apogeo. Visor Libros. Madrid.

CiRLơ, Juan-Eduardo: Diccionario de Símbolos. Nueva Colección Labor. Editorial Labor S. A. Madrid.

Chevalier, Jean y Gheerbrant, Alain (Col.) (1986): Diccionario de los símbolos. Editorial Herder, Barcelona.

Estravís, Isaac Alonso (1995): Dicionario da Língua Galega. Sotelo Blanco Edición, Santiago de Compostela.

MARCUSE, Herbert (1968): Eros e Civilização. Uma Interpretação Filosófica do Pensamento de Freud. 3. ed., Zahar Editores, Río de Janeiro.

Navarro Durán, Rosa (1998): Como leer un poema. Ariel Practicum, Barcelona.

PAZ, Octávio (1994): A dupla chama: amor e erotismo. Sililiano, S. Paulo.

(1996): Signos em rotação. 3. ${ }^{\mathrm{a}}$ ed. Editora Perspectiva S.A., S. Paulo.

Rábade Paredes, Xesús (1994): Poldros de Música. Fundación Caixa Galicia. Colección Esquío de Poesía.

RODRÍGUEZ-FER, Claudio (1998): Guia de investigación literária. Ediciones Júcar, Barcelona.

TADIÉ, Jean-Yves (1992): A crítica literária no século XX. Ed. Bertrand Brasil S. A., Rio de Janeiro. 